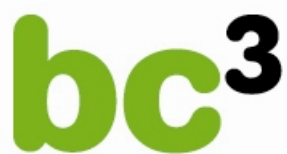

BASQUE CENTRE

FOR CLIMATE CHANGE

Klima Aldaketa Ikergai

\title{
International Support of Climate Change Policies in Developing Countries: Strategic, Moral and Fairness Aspects
}

Dirk Rübbelke

February 2010

BC3 WORKING PAPER SERIES

2011-02 
The Basque Centre for Climate Change (BC3) is a Research Centre based in the Basque Country, which aims at contributing to long-term research on the causes and consequences of Climate Change in order to foster the creation of knowledge in this multidisciplinary science.

The BC3 promotes a highly-qualified team of researchers with the primary objective of achieving excellence in research, training and dissemination. The Scientific Plan of BC3 is led by the Scientific Director, Prof. Anil Markandya.

The core research avenues are:

- $\quad$ Adaptation to and the impacts of climate change

- $\quad$ Measures to mitigate the amount of climate change experienced

- $\quad$ International Dimensions of Climate Policy

- $\quad$ Developing and supporting research that informs climate policy in the Basque Country

See www.bc3research.org for further details.

The BC3 Working Paper Series is available on the internet at http://www.bc3research.org/working_papers/view.html

Enquiries (Regarding the BC3 Working Paper Series):

Roger Fouquet

Email: roger.fouquet@bc3research.org

The opinions expressed in this working paper do not necessarily reflect the position of Basque Centre for Climate Change (BC3) as a whole.

Note: If printed, please remember to print on both sides. Also, perhaps try two pages on one side. 


\title{
International Support of Climate Change Policies in Developing Countries: \\ Strategic, Moral and Fairness Aspects
}

\author{
Dirk T.G. Rübbelke*
}

\begin{abstract}
International transfers in climate policy channeled from the industrialized to the developing world either support the mitigation of climate change or the adaptation to global warming. From an allocative efficiency point of view, transfers supporting mitigation tend to be Paretoimproving whereas this is not very likely in the case of adaptation support. We illustrate this by regarding transfer schemes currently applied under the UN Framework Convention on Climate Change (UNFCCC) and the Kyoto framework.

However, if we enrich the analysis by integrating distributional aspects, we find that international adaptation funding may help both developing and developed world. Interestingly this is not due to altruistic incentives, but due to follow-up effects on international negotiations on climate change mitigation. We argue that the lack of fairness perceived by developing countries in the international climate policy arena can be reduced by the support of adaptation in these countries. As we show - taking into account different fairness concepts - this might raise the prospects of success in international negotiations on climate change. Yet, we find that the influence of transfers may induce different fairness effects on climate change mitigation negotiations to run counter.

We discuss whether current transfer schemes under the UNFCCC and the Kyoto framework adequately serve the distributive and allocative objectives pursued in international climate policy.
\end{abstract}

Keywords: adaptation, climate change, fairness, Global Environmental Facility, international climate policy, mitigation, reciprocity, transfers

JEL classifications:H41, H87, Q54, Q56

Cite as: Rübbelke, D. (2011), International Support of Climate Change Policies in Developing Countries: Strategic, Moral and Fairness Aspects. BC3 Working Paper Series 2011-02. Basque Centre for Climate Change (BC3). Bilbao, Spain.

* Basque Centre for Climate Change (BC3), Alameda Urquijo 4, 48008 Bilbao, Spain, and IKERBASQUE - Basque Foundation for Science, 48011 Bilbao, Spain, email: dirk.ruebbelke@bc3research.org

Acknowledgements: We thank Aline Chiabai, Bettina Cooper and Marc Ringel for helpful comments. 


\section{Introduction}

Global warming poses one of the most challenging threats to our planet. As the IPCC (2007b: 56) points out: "Societies can respond to climate change by adapting to its impacts and by reducing GHG emissions (mitigation), thereby reducing the rate and magnitude of change». Accordingly, climate policy analytically comprises two different pillars: 1) mitigation of climate change, and 2) adaptation to climate change.

In the early days of climate policy, research focused strongly on mitigation strategies. It is largely acknowledged that significant greenhouse gas (GHG) emission reductions have to be achieved in order to effectively combat the threat of global warming. According to Edenhofer et al. (2011), such reductions require "a comprehensive global effort which includes both a complete change in the energy supply of industrialized countries and the establishment of lowcarbon systems in developing countries and emerging markets”. Industrialized and developing countries face the same challenge: Welfare threatening global warming and the risks attached can only be prevented if both groups of countries participate in international mitigation efforts. Adaptation policies had been largely disregarded until the mid-1990s. Only since then a sharply increasing research interest in adaptation activities has developed. ${ }^{1}$ The IPCC (2001a: 881) defines adaptation as an "adjustment in ecological, social, or economic systems in response to actual or expected climatic stimuli and their effects or impacts". These adjustments encompass changes in processes, practices, and structures to reduce potential damages or to take advantage of opportunities associated with climate change (see Stern 2007 and IPCC 2007a for examples).

The scientific discussion about adequate governmental mitigation and adaptation strategies is intense. Heterogeneity of properties of different policies complicates the analysis. While mitigation policies are global public goods (i.e., merits are non-excludable and there is nonrivalry in the consumption of these merits), ${ }^{2}$ adaptation impacts are mainly local or regional (Stern 2007: 406). Hence, “[i]n contrast to mitigation, the benefits of adaptation are excludable” (Barrett 2008a: 254) from individual countries’ point of view. This has farreaching implications for international climate policy, which is in the focus of our analysis.

While, “[t]here is undoubtedly a need for global action to reduce greenhouse gas emissions” (Adger 2001: 922), this might be different in the case of adaptation to climate change. As long as adaptation measures mainly yield excludable benefits, international free-rider incentives do

\footnotetext{
${ }^{1}$ As Smit et al. (1999: 199) stress, the concept of adaptation "is now a fundamental concern, and is receiving increasing attention". Notwithstanding the "increase in attention, the science of adaptation to climate change is still in its infancy” (Klein, Schipper and Dessai 2005: 580).

${ }^{2}$ Put it inversely, "global climate change is a public good (bad) par excellence” (Arrow 2007: 3).
} 
not arise and it is in individual countries' own interest to produce efficient adaptation, i.e. international coordination between countries is not required. Yet, these considerations taking only allocative-efficiency objectives of governments into account are insufficient for a comprehensive evaluation of the adequacy of climate-policy schemes.

Consequently, we enrich the analysis by complementing the reasons for and objectives of governmental intervention. From a public economic policy point of view as outlined by Musgrave (1959, 2008), objectives of governmental intervention should be either the pursuit of allocative efficiency or of a desired distribution of wealth. ${ }^{3}$ And as Boadway (1997: 768) points out, a great deal of what governments "do is redistributive in nature, rather than being a response to market failure in the classical sense”. A tool in climate policy that allows for both the pursuit of allocative and distributive objectives is the provision of international transfers from developed to developing countries. Such transfers are in the focus of our analysis.

Our objective is to specify different allocative and distributive sub-objectives which can be served by these transfers. In order to ascertain the adequacy of transfers for respective purposes, we elaborate the mechanisms for transfer provision under the UN Framework Convention on Climate Change (UNFCCC) and the Kyoto regime. In a first step, we focus our analysis on those mechanisms' capability of raising allocative efficiency in climate policy. In a second step, we examine whether beneficial effects of transfers with respect to distributional objectives may in turn help to augment allocative efficiency in international climate policy. It is investigated whether transfers can be employed strategically in order to generate such positive allocative follow-up effects.

In more detail, the paper is organized as follows. In Section 2, we will break the distributive and allocative objectives of governments down into four sub-categories of reasons for international transfers, i.e., granting assistance for development, serving moral obligations, Pareto-improvement of global public good provision, confidence building. Thereafter, in Section 3, the international transfer schemes are described and their potential for generating a Pareto-improved international climate policy is ascertained. We restrict our attention to transfer schemes which are supported by the UNFCCC's interim financial mechanism, i.e. the Global Environmental Facility (GEF). Transfers have to be beneficial (or at least not welfare diminishing) for both transfer receiving developing world and transfer providing developed world, since otherwise either the receptor or the provider would reject the transfers, i.e., they

\footnotetext{
${ }^{3}$ Stabilisation (securing the price-level stability and full employment) is considered to be a third reason justifying governmental intervention. For a rationale to largely omit the stabilisation branch in the adaptation context see Aakre and Rübbelke (2010a: 161).
} 
would not materialize. We distinguish between transfers supporting adaptation to climate change and those supporting mitigation of this change. International transfer schemes supporting adaptation in developing countries are comparatively new concepts and still have to find their place alongside mitigation and development aid concepts in the international finance and policy architecture. In Section 4, we investigate whether fairness-enhancing effects of transfers supporting adaptation in developing countries might exert a positive effect on international negotiations on mitigation and, in the course of this, on allocative efficiency in global climate change mitigation. If this is the case, adaptation finance could be employed strategically in order to improve the prospects of success in international climate policy. Two different concepts of fairness and different ways of providing transfers are distinguished. Interplays between both fairness concepts are elaborated. Section 5 concludes.

\section{Reasons for International Transfers in Climate Policy}

International law prescribes international transfers from the developed to the developing world. According to Article 4.3 of the UNFCCC, developed countries shall provide new and additional financial resources and transfer of technology needed by developing countries to meet the agreed full incremental costs of measures undertaken by developing countries in favour of the global environment. Furthermore, according to Article 4.4 of the UNFCCC, industrialized countries have to assist developing countries that are particularly vulnerable to the adverse effects of climate change also in meeting costs of adaptation to the change.

Yet, the UNFCCC did not appear from nowhere but was adopted at the 1992 "Rio Earth Summit" and 192 countries around the world have joined it voluntarily. We are interested in the reasons that motivated countries to commit to international transfer payments. We may distinguish between four different reasons why governments of countries intervene and provide transfers:

a) granting development assistance (distribution),

b) serving moral obligations, e.g. due to historical responsibilities (distribution),

c) Pareto-improvement of global public good provision and of the generation of positive international externalities (allocation), ${ }^{4}$

d) strategic confidence-building by raising fairness (indirectly: allocation).

This scheme is in line with the public economic policy perspective suggested by R.A. Musgrave (1959, 2008) which indicates that both distributional and allocative aspects justify

\footnotetext{
${ }^{4}$ The criterion of Pareto-improvement implies that both the transfer providers as well as receptors do - at least not lose welfare. If this criterion would not be met, countries tend to reject the receipt/payment of transfers and transfers will not materialize.
} 
governmental intervention. Hence, governments should not only act as agents correcting market imperfections (allocation) but might also pursue policies helping to attain a desired distribution of welfare. Although R.A. Musgrave's concept distinguishing governmental functions gave little attention to the foreign sector when it was introduced, the international sector can be comfortably included into this concept as P.B. Musgrave (2008: 343) illustrates. The particular "desired" income distribution (or redistribution) is of course affected by perceived moral obligations and consequently (a) and (b) can be both subsumed under the category of "distribution”. While (c) refers to improving welfare (allocation) in general by raising the level of climate-change related public goods, the last item (d) - although similar to (c) - relates to the prerequisite of efficient global climate policy: the attainment of an internationally agreed architecture for climate change mitigation. Transfer schemes raising trust might trigger a higher willingness of countries which were (feeling) treated unfairly before to participate in international agreements and may thence indirectly improve the allocation.

Next, main features of the four reasons are shortly discussed.

\subsection{Distribution Aspects $(a+b)$}

As Schelling points out, a "strong argument for trying seriously to slow climate change is that developing countries are vulnerable and we care” (Schelling 1992: 7) and any "action combating global warming will be, intended or not, a foreign aid program” (Schelling 1997: 8). The World Bank (2006: 28) expands the respective reasoning to adaptation aspects: “All countries are vulnerable to climate change and instability in weather patterns but the poorest countries and the poorest people within them are most vulnerable, having the least means to adapt”. Hence, international support of mitigation activities but also of adaptation to climate change in poor developing countries can be regarded as a foreign aid supporting sustainable development. $^{5}$

Yet as Barrett (2007a) explains: "the motivation for providing adaptation assistance is different than for providing development assistance”. Historically the industrialized world's economic development is the main driver for global warming, while developing countries tend to be the main victims of this warming. Or as Barrett (2007a) remarks: “The rich countries did not make the poor countries poor, but they are largely responsible for the accumulation of greenhouse gases in the atmosphere”. Therefore, based on, e.g., the polluter-pays principle, it

\footnotetext{
${ }^{5}$ In principle the need for mainstreaming adaptation to climate change into development planning and ongoing sectoral decision-making is increasingly recognised (Klein et al. 2007). One of the referees adverted to the fact that the wealth level also differs between individual developing countries (and not only between industrialized and developing countries); hence, likewise the need for international support in climate policy varies.
} 
could be argued that there is a moral obligation for the industrialized countries to protect the poor countries from the negative consequences of their GHG emitting activities. ${ }^{6}$ Protection can be provided by slowing climate change or by helping the developing countries to adapt to ongoing climate change. ${ }^{7}$ This international support has also implications for the attainment of allocative efficiency, as we will outline in the subsequent paragraphs.

\subsection{Allocation Aspects (c+d)}

Climate protection is a global public good, since nobody in the world can be excluded from the merits of any individual agent's protection activities and there is no rivalry in the consumption of their merits. A standard result of the theory of public goods is that public goods would be undersupplied by voluntary contributions (Bergstrom, Blume and Varian 1986, Cornes and Sandler 1996), since free- or easy-riding incentives of agents or countries exist. Furthermore, uncoordinated voluntary provision tends to be produced in a costineffective way (i.e., a given level of public good provision is not attained at least costs) and consequently, resources are wasted which otherwise would be available, e.g., for additional public-good provision.

While inefficiency of public good provision (due to free-riding incentives and costineffectiveness) can be overcome on a national level by intervention of the national government, there exists no such coercive authority (like a government) on the international level and consequently, other cures for the underprovision of the public good 'climate protection' have to be sought.

As Buchholz and Konrad (1995) demonstrate, unconditional income redistribution may help to address cost-effectiveness problems in public good provision. Transfers channeled from a country which is less productive in mitigating climate change towards a country which is more productive, will induce an international reallocation of mitigation activities. The new allocation of mitigation activities is more cost-effective, i.e., less resources are wasted which can now be applied to raise public good provision. At the same time, global welfare may be augmented. This implies that as long as the public good 'climate protection' can be produced more cheaply in the developing world, transfers from the industrialized world tend to raise global climate change mitigation levels and may raise welfare of both the industrialized as well as the developing world (see also Jayaraman and Kanbur (1999) for the influence of

\footnotetext{
${ }^{6}$ As Lange, Vogt and Ziegler (2007) find out in their empirical analysis based on data from a world-wide survey of people involved in climate policy, the polluter-pays rule and the accompanying poor losers rule are the most widely accepted equity principles.

${ }^{7}$ For a discussion of principles for fair adaptation to climate change in a broader context, see, e.g. Paavola and Adger (2006) and Grasso (2007).
} 
foreign aid on international public good provision). Yet, international transfers in a climatechange context are generally provided in a conditional way, which helps to mitigate free-rider incentives, as we will discuss in more detail in the subsequent section. However, as we will also argue, transfers will have quite different implications for adaptation than for mitigation policies.

Moreover, free-rider incentives may also be addressed by international coordination between countries. By means of international negotiations conflicting positions of individual countries can be discussed and agreements can be sought to break the deadlock in international climate policy. However, as Lange, Vogt and Ziegler (2007: 546) point out: “In a world where no single party will provide the common good in sufficient quantity and no institution exists to enforce cooperation, an agreement will only be accepted by the parties if it assessed to be beneficial in terms of costs and benefits and if it is perceived to be fair”. Consequently, both economic efficiency and fairness are considered to be prerequisites for attaining an international agreement on climate change. A country's government can strategically raise the international fairness perceived in other countries by supporting confidence-building activities and - as we argue - adaptation transfers from the industrialized to the developing world can take the role of a vehicle enhancing fairness as perceived by developing countries. To our knowledge, in the literature discussing international adaptation support this line of reasoning has been largely neglected so far.

\subsection{Analysis of Distribution and Allocation Aspects}

Since we are concerned with transfers in international climate policy which are required to be additional to development assistance transfers (see Article 4.3 of the UNFCCC), development aid motives (a) will play a subsidiary role in our analysis although we address the close links between adaptation and development aid in our discussion of the appropriateness of the Global Environmental Facility's funding schemes for adaptation support. As Klein, Schipper and Dessai (2005: 584) stress, "promoting development and equity is not a direct objective of the UNFCCC, and there is concern that scarce funds for mitigation and adaptation will be diverted into more general development activities.” Therefore, we consider development effects (which go beyond the retrieval of development otherwise lost due to climate change) of transfers in international climate policy more as a co-benefit than as a motivation for such transfers.

In our analysis we will especially consider the ways in which allocation objectives (c) and (d) can be served via the use of international transfers, and then, elaborate on the contribution which the pursuit of normative moral obligations (b) may provide for attaining an improved outcome in international climate policy. 


\section{Adaptation and Mitigation Funding: Allocation Aspects}

Because the UNFCCC constitutes the basic legal framework for international climate policy and the Conference of Parties of the UNFCCC selected the Global Environmental Facility (GEF) as the UNFCCC's interim financial mechanism at its first meeting in 1995, we focus in our analysis on transfer schemes in which the GEF is involved.

In line with Article 4 of the UNFCCC, the GEF is responsible for providing financial assistance to developing countries in realizing incremental climate protection activities. Such incremental activities are climate-protecting actions of developing countries that would not have been realized without the GEF's support. The scenario without these actions is called the baseline. $^{8}$

The funds managed by the GEF are financed by industrialized countries. The Facility is committed to channel these funds with global benefit orientation towards projects established in developing countries. Transfers are conditional, i.e., transfers are only granted for incremental global environmental protection activities.

Besides projects in the focal area of climate change, the Facility supports projects in five additional focal areas: biological diversity, international waters, land degradation (primarily desertification and deforestation), ozone layer depletion, and persistent organic pollutants.

The GEF promotes synergies in seeking multiple environmental benefits and the rationale championed by the GEF in doing this includes: 1) achieving sustained flow of global environmental benefits, 2) securing multiple global environmental benefits, 3) avoiding negative impacts, and 4) avoiding future adaptation cost (GEF 2010a: 6). The GEF, e.g., intends to "orient the programming of resources for managing forest ecosystems to securing multiple environmental benefits, particularly those related to the protection and sustainable use of biodiversity, climate change mitigation and adaptation, and combating land degradation” (GEF 2010a: 9).

While the strategy of exploiting synergies looks very attractive as long as global benefits arise in the GEF's focal areas, problems impend in the attribution of funding in case environmental co-benefits are local. This is due to the Facility's global benefit orientation. Let us have a closer look at the GEF's funding concepts and the involved difficulties in the following subsections.

\footnotetext{
${ }^{8}$ Consensus on baselines is "difficult to reach, both for lack of information and of clear country strategies ... and for the risk of strategic behaviour of recipient countries” (Pearce 1995: 175).
} 


\subsection{Funding Mitigation}

Conditionality of transfers has the attractive property of reducing the effective price of desired mitigation activities from the recipient's point of view. The decline in the effective price causes developing countries' demand for such activities to rise. There is a large strand of public finance literature discussing the capability of such price-influencing subsidy or matching schemes to generate a Pareto-improved public good provision (see, e.g., Guttman 1978, Althammer and Buchholz 1993, Falkinger 1996, Boadway, Song and Tremblay 2007, Buchholz, Cornes and Rübbelke 2011). Because the GEF scheme provides incentives to raise mitigation efforts in those regions (i.e., developing countries) where they can be accomplished at least cost, it contributes to the cost-effectiveness of global climate change mitigation.

Figure 1 depicts an individual developing country's choice according to the consumption of a private goods bundle $\mathrm{y}$ and the global public environmental good provision $\mathrm{x}$. Both commodities are supposed to represent normal goods. Other agents' provision of public goods is assumed to be exogenously given. A welfare maximizing nation would choose the allocation where the price ratio between both goods is equal to the marginal rate of substitution between both goods. In the situation before the subsidization via conditional transfers, the respective efficient allocations are depicted by income expansion path $\mathrm{E}^{\text {old }}$. For the given national income (indicated by $\left.\mathrm{B}^{\text {old }}\right)$, the nation chooses the allocation $\left(\mathrm{y}_{1}, \mathrm{x}_{1}\right)$, i.e., the point of tangency between budget constraint $\mathrm{B}^{\text {old }}$ and indifference curve $\mathrm{I}^{\text {old }}$. Hence, the global environmental protection provided by the considered country is $x_{1}$. In the situation where the GEF subsidization scheme is applied, the income expansion path pivots upwards, but only partially and only in the area beyond the baseline protection level $\mathrm{x}_{1}$, since only those protection measures are subsidized which are not included in the baseline scenario.

This simple illustration helps to understand how the environment protection level can be raised (to $\mathrm{x}_{2}$ ) through referring to the concept of financing incremental costs. Yet, the criteria determining the extent of financial support by the GEF - and therefore the slope of $E^{\text {new }}$ - still remain ambiguous: by the agreed full incremental cost conception the UNFCCC only gives a vague specification of the transfer level the GEF should channel to developing countries.

As Pearce (1995: 168-170) as well as Heintz and Tol (1996: 2-3) point out, the so-called net incremental cost (NIC) and the gross incremental cost (GIC) can be regarded as the lower and upper bounds delimiting the agreed full incremental cost. The GIC conception does not net out the domestic benefits gained by the developing country as the host of the incremental action. The NIC conception nets out the domestic benefits in the shape of ancillary benefits and direct economic benefits, e.g., of saved energy expenses or a direct improvements in productivity. 
According to the IPCC (2001b), ancillary benefits "are the monetized secondary, or side benefits of mitigation policies on problems such as reductions in local air pollution associated with the reduction of fossil fuels, and possibly indirect effects on congestion, land quality, employment, and fuel security." As Gielen and Chen (2001: 258) point out, the "fringe benefits” of local air pollution reduction are very significant in developing countries and hence GHG emission mitigation can be achieved at low additional cost.

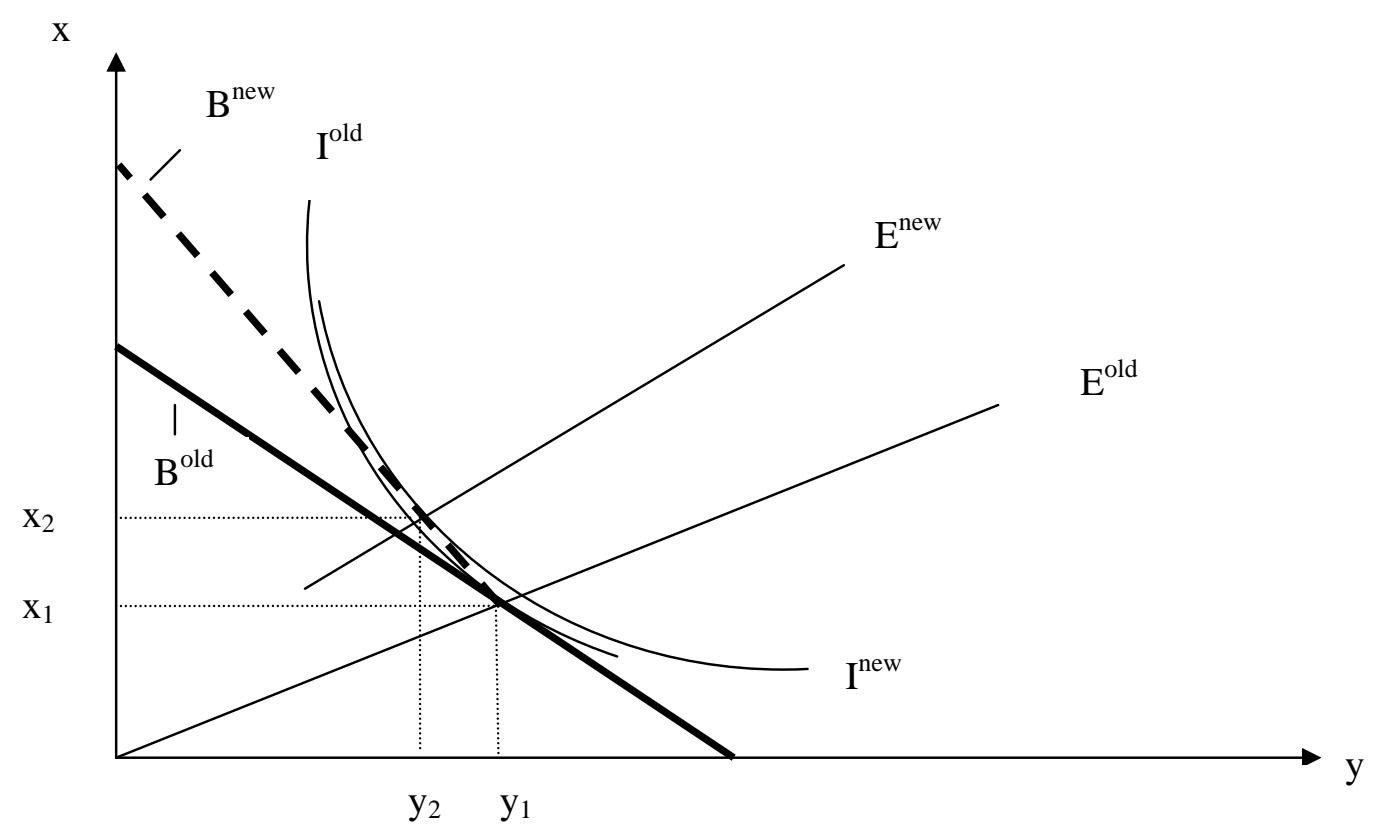

Figure 1: Illustration of the GEF Transfer Scheme. ${ }^{9}$

The application of the NIC concept is appropriate, if the involved agents exclusively aim at maximizing global benefits with a given amount of GEF funds. Yet, then the host countries would only enjoy global benefits free of charge, while they have to pay for the received domestic benefits. The transfer-paying industrialized countries also benefit from the GEF scheme: by supporting mitigation projects in developing countries which are in general more cost-effective options than domestic projects, industrialized countries enjoy mitigation benefits at reduced costs. Since both developing and industrialized world obtain a welfare gain from the impacts of the conditional transfers, the scheme augmenting mitigation is Paretoimproving.

Having outlined the GEF concepts for supporting mitigation projects, we will illustrate in the subsequent section that these concepts are not appropriate for the support of adaptation.

\footnotetext{
${ }^{9}$ In the case of a subsidy rate of 100 percent, beyond $\mathrm{x}_{1}$ the path $\mathrm{E}^{\mathrm{new}}$ would be a vertical line. If the rate is below 100 percent, there may be exceptions to our results, e.g. if it holds for the utility function $U$ that $U=x y$. Then, no new optimum will be induced.
} 


\subsection{Funding Adaptation}

As Müller (2008: 4) points out, "adaptation funding is seen by most developing countries not as a matter of 'donations' but as one of costs imposed by developed countries, and as such as debt incurred by them". He reasons that neither of the traditional official development assistance (ODA) funding modes “are seen to be appropriate payment modes”, and that the acceptability of international adaptation funding depends amongst other things on whether the respective funds are `new and additional’ to traditional ODA (Müller 2008: 21). ${ }^{10}$

Yet, due to the strong interconnection between (sustainable) development and adaptation to climate change, the distinction between development assistance and adaptation assistance and therefore the ascertaining of additionality - becomes a difficult task. In addition, the separation of development and adaptation assistance may not be desirable because synergies of policies addressing both fields of assistance might get lost otherwise. In response to the UNFCCC guidance from the Seventh Conference of Parties in Marrakesh the GEF established two different funds which indeed simultaneously address both fields. These are the Least Developed Countries Fund (LDCF) and the Special Climate Change Fund (SCCF) which were launched in 2001. ${ }^{11}$ The GEF administers both funds with the World Bank acting as trustee. ${ }^{12}$

Projects under the LDCF and the SCCF link adaptation to development and mitigate risks of climate change by supporting adaptation in key development sectors like agriculture and water. ${ }^{13}$ More precisely, funding is subject to the additional costs of making development climate-resilient. As Le Goulven (2008: 7) points out: “Conceptually additional costs are the difference between development in the absence of climate change and development taking into account the adverse effects of climate change.” As the GEF (2006: 10) stresses, "it may be difficult to assess ex-ante the additional cost of adaptation, as the construction of detailed baseline and adaptation scenarios can be quite complex, time consuming, and imprecise.”14

The UNDP (2009: 25) points out that some countries criticize the entire governance structure of the LDCF and SCCF: "Against the backdrop of the processes to enhance global aid effectiveness, they are keen to look at and propose ways in which donor contributions could

\footnotetext{
${ }^{10}$ The 2009 Copenhagen Accord took claims for additionality into account: "Scaled up, new and additional, predictable and adequate funding as well as improved access shall be provided to developing countries [...] to enable and support enhanced action on mitigation [...], adaptation, technology development and transfer and capacity-building, for enhanced implementation of the Convention.”

${ }^{11}$ For an overview of adaptation funds, also of those unrelated to the GEF, see, e.g., Le Goulven (2008: 4-5) and van Drunen et al. (2009: 19).

${ }^{12}$ As of May 31, 2010, cumulative net funding decisions taken by the Council and the CEO of the LDCF amounted to USD eq. $135 \mathrm{M}$, the respective amount concerning the SCCF was USD eq. $109 \mathrm{M}$ (GEF 2010b).

${ }^{13}$ Other fields of the two funds' project financing are technology transfer and capacity building.

14 Therefore, the GEF has developed a proxy - the sliding scale. For the features of this proxy see COWI and IIED (2009).
} 
be channelled directly to countries' financial management systems, without GEF and UNDP involvement.”

Regarded from the Facility's perspective, LDCF and SCCF are only two possible tracks to support adaptation to climate change. The third operational track used to be the Strategic Priority "Piloting an Operational Approach to Adaptation” (SPA), which has been a part of the GEF Trust Fund. The SPA has been supporting pilot and demonstration projects on adaptation. ${ }^{15}$ By September 2009, all the SPA funding has been allocated and for the GEF-5 replenishment (2010-2014) all adaptation-related work of the GEF will be financed solely through the LDCF and SCCF. While the GEF Trust Fund's support of activities must generate primarily global environmental benefits, the same is not required with respect to the support stemming from the other GEF managed funds (LDCF and SCCF): “Although guidance from the parties is not explicit on the point, the GEF's position is that the 'global environmental benefits’ test does not apply to these funds” (Burton, Diringer and Smith 2006: 14). However, as Burton, Diringer and Smith (2006: 14) note, “there remains a widespread perception among potential recipients that it does.”

A fourth fund, the Adaptation Fund (AF), is like the LDCF and the SCCF distinct from the GEF Trust Fund. In contrast to the LDCF and SCCF, it falls under the framework of the Kyoto Protocol and will be managed and supervised by a special Adaptation Fund Board. This Board comprises 16 members and 16 alternate members representing relevant country groups. Developing countries hold the overall majority of seats in the Board. Special seats have been given to the Least Developed Countries and the Small Island Developing States. The GEF was invited only to provide secretariat services. The AF is to be financed with a share of proceeds from clean development mechanism (CDM) project activities and is also to receive funds from further sources. In Decision 1/CMP.3 of the Conference of the Parties serving as the meeting of the Parties to the Kyoto Protocol it was stipulated "that developing country Parties to the Kyoto Protocol that are particularly vulnerable to the adverse effects of climate change are eligible for funding from the Adaptation Fund to assist them in meeting the costs of adaptation”. ${ }^{16}$

\subsection{The Necessity to Find New Paths for the Funding of Adaptation}

The establishment of new funds in addition to the GEF Trust Fund is not very surprising if we take a look at the different properties of climate change mitigation and adaptation options. The

\footnotetext{
${ }^{15}$ Möhner and Klein (2007: 8) describe the outline of the series of scenarios which is required for determining the GEF funding under the SPA.

${ }^{16}$ The expected amount of available resources is USD 250-350 M by 2012 (see http://www.adaptation-fund.org/).
} 
mitigation of global warming can be regarded as a global public good as the benefits derived from this mitigation are enjoyed worldwide. The attractiveness for industrialized countries to support - via the GEF - mitigation activities in the developing world lies in the fact that GHG abatement is in general less expensive in the developing world than at home. By the exploitation of efficiency gains, resources are set free which may be shared (depending on the incremental-cost rule) between industrialized and developing countries raising both countries' welfare.

In contrast to the global benefits of mitigation projects, the benefits of adaptation to global warming are mainly enjoyed only within the region where the adaptation measure is implemented. ${ }^{17}$ Since the benefits of adaptation are local, rich countries gain nothing directly by assisting poor countries to adapt (Barrett 2008b). Hence, as the industrialized countries give up some of their wealth while only the developing countries benefit, the transfer does not meet the criterion for Pareto-improvement (i.e., no country loses welfare while at least one country's welfare is raised), ${ }^{18}$ as long as we ignore possible distributional benefits obtained by the industrialized countries (e.g., from enjoying a more equitable world).

Yet some global benefits may arise from adaptation measures in developing countries, but in general positive global spillovers of adaptation to climate change are much 'less direct' than the positive externalities of climate change mitigation. Adaptation options in the shape of improvements of trans-boundary river basin management in Asian developing countries, for example, might yield such 'less direct' positive spillovers (e.g., the prevention of refugees fleeing from flooding towards the industrialized world). However, such spillovers are also received from mitigation measures in developing countries (in addition to the global direct mitigation effects; see also Aakre and Rübbelke (2010b: 778) on direct and indirect effects). Adger et al. (2001: 699) employ the term 'secondary consequences' in order to denote 'more indirect' consequences of climate change like large-scale migration towards the industrialized world caused by population displacement as a result of drought or sea-level rise.

Effects of adaptation and mitigation options are shortly discussed in the Appendix and categorized in Table A.1 according to their degree of directness and the delay of their occurrence. Delayed positive effects tend to be less attractive from a policymaker's point of view (arising future benefits might be discounted which attenuates their magnitude in present-

\footnotetext{
${ }^{17}$ However, Anantram and Noronha (2005: 8) name some adaptation goods which they regard to be globally public, e.g., early warning systems, climate monitoring systems, and afforestation programmes.

${ }^{18}$ As Barrett (2007b: 5) remarks: "From the perspective of self-interest, the incentives for rich countries to assist poor countries to adapt are weak.”
} 
value terms). As we can observe from Table A.1, mitigation policies generate direct as well as indirect global effects, while adaptation only generates indirect global effects.

Indirect global effects in addition to distributional aspects might motivate industrialized countries to provide international transfers supporting adaptation to climate change in developing countries. Yet, in the subsequent section we add another argument in favour of such transfers, i.e. strategic confidence-building by raising fairness.

\section{Strategic Role of Adaptation Finance}

In this section we discuss whether adaptation support via transfers could be a vehicle for industrialized countries to raise the prospects of success of international negotiations on climate change mitigation and of attaining a Pareto-improved outcome. The basic idea is that industrialized countries' support of adaptation in developing countries might induce developing countries to feel treated more fairly and this in turn might have a positive impact on their willingness to contribute to international mitigation efforts. Put it differently, the industrialized world invests in local adaptation benefits in developing countries in order to motivate them to contribute to the provision of global benefits.

There is a variety of factors which may influence the perception of fairness and there is disagreement about the proper way in which fairness should be measured (see, e.g., Fehr and Gächter 2000: 162-163 and Bolton and Ockenfels 2005: 958-960). In our analysis we distinguish between:

1) fairness perception based on observations in the course of current international environmental negotiations/policy: perceived fairness depends on conjectures about the other negotiating agents' intentions, and

2) fairness perception based on past experiences: perceived fairness depends on consequences of other agents' former actions. ${ }^{19}$

Let us next have a closer look at these two perspectives and their implications for international negotiations' prospects of success.

\subsection{Fairness Observed in Current Processes (Intention Driven)}

Already Kahneman, Knetsch and Thaler (1986a: S285) pointed out that "[t]he absence of considerations on fairness and loyalty from standard economic theory is one of the most striking contrasts between this body of theory and other social sciences - and also between economic theory and lay intuitions about human behavior”. Owing to this critique, new

\footnotetext{
${ }^{19}$ According to Ikeme's (2003: 201) findings from a survey of the literature, developing countries' conception of environmental justice emphasizes that the past must play a fundamental role in addressing present entitlements.
} 
concepts have been developed to integrate fairness aspects into economic analysis. For instance Geanakoplos, Pearce and Stacchetti (1989) stressed the role of beliefs in gametheoretical settings and based on their framework allowing payoffs to depend on players' beliefs and actions, Rabin (1993) developed the concept of kindness functions. Via these kindness functions, which measure how kind a player $i$ is to another player $j$, he incorporates fairness in his analysis of different 2x2 game-theoretical settings. In Rabin's framework agents may prefer to sacrifice some of their material well-being for fairness reasons, i.e. either for helping those who are kind to them or for punishing those who are unkind (Rabin 1997: 1). The expected utility $U_{i}$ which an agent $i$ maximizes depends on his strategy $a_{i}$ which he chooses from his strategy set $S_{i}$, on his beliefs $b_{j} \epsilon S_{j}$ about what strategy the other agent is choosing and player $i$ 's beliefs $c_{i} \epsilon S_{i}$ about what player $j$ believes player $i$ 's strategy is. The expected utility, which is consisting of material utility and a fairness component, can therefore be expressed:

$U_{i}\left(a_{i}, b_{j}, c_{i}\right) \equiv \pi_{i}\left(a_{i}, b_{j}\right)+\tilde{f}_{j}\left(b_{j}, c_{i}\right) \times\left[1+f_{i}\left(a_{i}, b_{j}\right)\right]=\pi_{i}\left(a_{i}, b_{j}\right)+F_{i}\left(a_{i}, b_{j}, c_{i}\right)$, where $\pi_{i}\left(a_{i}, b_{j}\right)$ is the expected material utility and the other term(s) $F_{i}\left(a_{i}, b_{j}, c_{i}\right)$ convey the idea of fairness. $\tilde{f}_{j}\left(b_{j}, c_{i}\right)$ is player $i$ 's belief about how kind the other player is, while player $i$ 's kindness to player $j$ is given by kindness function $f_{i}\left(a_{i}, b_{j}\right)$.

A player tends to pursue strategies benefiting (also) the other player, if he believes that the opponent player is playing in a kind - and not in a mean - way. Thus, conversely, if a government conjectures unkind behaviour by opponents in the course of international climate negotiations, it tends to retaliate. However, fairness will influence the government the less, the higher the marginal material cost of retaliation.

As Pittel and Rübbelke (2008) argue, international negotiations on mitigation can either be depicted as a prisoner's dilemma or as a chicken game. The game of chicken is according to Camerer (1997: 171) "perhaps the ideal game for contrasting fairness and self-interested preferences.” To this kind of game we apply a numerical example for fairness adjustment which was proposed by Camerer and Thaler (2003), but we express the material payoffs in a more general way. We apply this setting to international negotiations on climate change mitigation as follows: The chicken strategy in the game outlined by Camerer and Thaler (2003) is regarded to be equivalent to the strategy "participate” in an international climate agreement and the dare strategy is equivalent to "no participation".

Taking into account the risk of a disastrous outcome of climate change in the case in which no country plays participate, the material pay-offs (i.e., net benefits, taking into account the 
benefits of climate policy minus the costs of taking action) of countries A and B depicted in Figure 2 might be such that $0<A_{A}<C_{A}, B_{A}>D_{A}>A_{A}, 0<A_{B}<B_{B}, C_{B}>D_{B}>A_{B}$, and let us initially assume that $0<\alpha_{A}^{I}<\frac{C_{A}-A_{A}}{0.5}, \quad \alpha_{A}^{I}<\frac{B_{A}-D_{A}}{0.75}, 0<\alpha_{B}^{I}<\frac{B_{B}-A_{B}}{0.5}$ and $\alpha_{B}^{I}<\frac{C_{B}-D_{B}}{0.75}$, i.e., we face a chicken-game setting for both the game with and without fairness adjustments. In both the game with and without fairness adjustment the Nash equilibria with pure strategies are (no participation, participation) and (participation, no participation).

\begin{tabular}{|c|c|c|}
\hline B's strategy & no participation & participation \\
\hline no participation & $A_{A}, A_{B}$ & $B_{A}, B_{B}-0.5 \alpha_{B}^{I}$ \\
\hline participation & $C_{A}-0.5 \alpha_{A}^{I}, C_{B}$ & $D_{A}+0.75 \alpha_{A}^{I}, D_{B}+0.75 \alpha_{B}^{I}$ \\
\hline
\end{tabular}

Figure 2: Game with Fairness-Adjusted (intention driven) Payoffs.

The fairness adjustment (or adjustment to the lack of fairness) takes place in the way that $F_{i}\left(a_{i}, b_{j}, c_{i}\right)=-0.5 \alpha_{i}^{I}$ (with $\alpha_{i}^{I}>0, i=A, B$ and $i \neq j$ ), if there is asymmetry in the countries' behaviour and $i$ is the participating party. $F_{i}\left(a_{i}, b_{j}, c_{i}\right)=-0.5 \alpha_{i}^{I}$ can be interpreted as the discomfort of $i$ from being treated in an unfair way. Agent $i$ suffers from the unilateral noncooperation of its opponent $j$ and the associated fairness adjustment implies a higher tendency for “negative reciprocity”. In contrast, a tendency for "positive reciprocity” prevails, if both countries participate. The kindness/fairness enjoyed due to the respective opponent's participation and contribution to climate protection implies a fairness adjustment with a positive factor, i.e., $F_{i}\left(a_{i}, b_{j}, c_{i}\right)=+0.75 \alpha_{i}^{I}$.

Yet, Madani (2010: 234) advises caution with respect to the identification of the game conditions and their potential alterations: "Changes in the conflict can change the payoff functions and values of players over time. Changing game conditions can alter the game's structure, its equilibria, and the results provided by game theory". ${ }^{20}$ Accordingly, let us have a look at different levels of fairness adjustment.

Depending on the parameterization of the model and the magnitude of the increase in fairness adjustment, a rise in the values of $\alpha_{i}^{I}$ may turn the initial chicken-type game into a prisoner's dilemma game where $\alpha_{A}^{I}<\frac{B_{A}-D_{A}}{0.75}, \quad \alpha_{B}^{I}<\frac{C_{B}-D_{B}}{0.75}, \quad \alpha_{A}^{I}>\frac{C_{A}-A_{A}}{0.5}$ and $\alpha_{B}^{I}>\frac{B_{B}-A_{B}}{0.5}$. Then the

\footnotetext{
${ }^{20}$ For a discussion of transitions in game structures depicting negotiations on climate change, see also Pittel and Rübbelke (2010).
} 
dominant strategy is playing "no participation”. For a different parameterization of the model, the same change in $\alpha_{i}^{I}$ may yield $\alpha_{A}^{I}>\frac{B_{A}-D_{A}}{0.75}, \alpha_{B}^{I}>\frac{C_{B}-D_{B}}{0.75}, \alpha_{A}^{I}<\frac{C_{A}-A_{A}}{0.5}$ and $\alpha_{B}^{I}<\frac{B_{B}-A_{B}}{0.5}$. Then the dominant strategy for both agents is playing "participation”. There are several further possible constellations of the game varying with fairness adjustment levels, e.g., where one agent holds the dominant strategy to cooperate while the other agent does not.

Yet, with growing values for fairness adjustment, i.e. with a rising discomfort from unfair solutions, the game would finally take the shape of a coordination game of the stag-hunt type. ${ }^{21}$ This would be the case if the values of $\alpha_{i}^{I}$ become so large that $\alpha_{A}^{I}>\frac{C_{A}-A_{A}}{0.5}, \alpha_{A}^{I}>$ $\frac{B_{A}-D_{A}}{0.75}, \alpha_{B}^{I}>\frac{B_{B}-A_{B}}{0.5}$ and $\alpha_{B}^{I}>\frac{C_{B}-D_{B}}{0.75}$. As can be observed from Figure 2, in this case the equilibria or so-called fairness equilibria become (no participation, no participation) and (participation, participation), i.e., outcomes with pure strategies can be either worse or better than in the standard case without fairness adjustment.

Summarized, situations in which one agent is extracting benefits at the expense of the opponent (as in the Nash equilibria of the standard chicken game without fairness adjustment) become relatively unattractive, because the agent who is worse off in material terms additionally suffers from the perceived unfairness of the situation.

As stated before, the (un-)fairness regarded by Rabin (1993) refers to motives of agents playing the game and if one agent supposes, for example, that the opponent will play a specific strategy because of hostile motives, this will induce him to be more willing to retaliate although it will be at the expense of his material payoff. Or as Smith (2003: 467) puts it, the game setting is "based on other-regarding, in addition to own-regarding, preferences". However, as Falk and Fischbacher (2006: 309) stress, "[k]indness comprises both the consequences as well as the intention of action”. Consequently, not only the beliefs about the other agents' motives in the game may influence the perceived fairness of policies, but also past experiences with the opponent might play a role.

\subsection{Fairness Perception Due to Past Experiences (Consequence Driven)}

Kahneman, Knetsch and Thaler (1986a) illustrate the influence of a company's past pricing and policy on consumers' view of the fairness of current prices charged by that firm. In environmental policy, an agent's past efforts to preserve the nature or his lack of such efforts in the past (e.g., by polluting the environment quite heavily) might influence the other agents' perception and assessment of how (un-)fair or (un-)kind his conduct is. As Kahneman,

\footnotetext{
${ }^{21}$ For depictions of prisoner's dilemma, chicken and stag-hunt games in the context of water resource conflict resolution see Madani (2010).
} 
Knetsch and Thaler (1986b: 731) argue, people tend to expect a substantial level of conformity to community standards and they also tend to adapt their views of fairness to the norms of actual behaviour. Smith (2003: 467) stresses that "people may use social-grown norms of trust and reciprocity [...] to achieve cooperative states superior to individual rational defection outcomes".

Ringius, Torvanger and Underdal (2002) discuss such standards and norms by considering different fairness principles and different types of burden sharing proposals in international climate policy. A fairness principle widely accepted in the climate policy arena (see Lange, Vogt and Ziegler 2007) is the polluter pays principle, ${ }^{22}$ which is closely related to the burden sharing concept of 'historical responsibility' for global warming. ${ }^{23}$ Grasso (2010) characterizes (differentiated) historical responsibility as an equity criterion. ${ }^{24}$

Developing countries argue that mainly the industrialized countries caused global warming and the associated damages and as Najam, Huq and Sokona (2003: 225) remark, "the citizens of the north will continue to remain disproportionately responsible for global emissions well into the future, despite whatever growth might happen in the south over the next few decades”. In the past, the industrialized countries could develop their economies disregarding the consequences on the global climate. Developing countries tend to consider it as unfair that they will have to suffer from climate change mainly caused by industrialized countries and are nevertheless now requested to also contribute to the combat of global warming. Therefore, any efforts of industrialized countries to include developing countries in international negotiations might be regarded as a hostile act. Focusing on these fairness aspects based on past experience and omitting the intention driven fairness aspects described in Figure 2 (and by Camerer and Thaler 2003), the negotiation situation can be illustrated by Figure 3, where B represents the group of developing countries and A the group of industrialized countries.

In this scenario the developing countries regard their own contributions to mitigation as unfair per se, because the industrialized countries' past activities raised the climate change problem. Of course, the situation where industrialized countries do not participate while developing countries do, is regarded to be more unfair (i.e., the historical adjustment is $F^{H}=-0.75 \alpha^{H}$ ) than a situation of mutual participation (i.e., the historical adjustment is $F^{H}=-0.5 \alpha^{H}$ ).

\footnotetext{
${ }^{22}$ Neumayer (2000: 187) points out: "historical accountability is buttressed by the polluter-pays-principle which has been embraced by the OECD countries as long ago as 1974”. According to Neumayer (2000: 187-188) historical responsibility is also supported inter alia by the principle of equality of opportunity.

${ }^{23}$ Bastianoni, Pulselli and Tiezzi (2004: 254) claim that the scientific community should "draw more attention to the need for a fair accounting method to create a GHG inventory which also assigns responsibility for emissions.”

${ }^{24}$ Shue (1999: 534) remarks: "Those societies whose activities have damaged the atmosphere [...] ought to bear sufficiently unequal burdens henceforth to correct the inequality they have imposed”. As a justification for this claim he provides a principle of equity; for this principle see Shue (1999: 534).
} 


\begin{tabular}{|c|c|c|}
\hline A's strategy & no participation & participation \\
\hline no participation & $A_{A}, A_{B}$ & $B_{A}, B_{B}-0.75 \alpha^{H}$ \\
\hline participation & $C_{A}, C_{B}$ & $D_{A}, D_{B}-0.5 \alpha^{H}$ \\
\hline
\end{tabular}

Figure 3: Chicken Game with Historical-Fairness Adjustment; with $D_{B^{-}} 0.5 \alpha^{H}>A_{B}$, $0<\alpha^{H}<\left(B_{B}-A_{B}\right) / 0.75, \alpha^{H}>\left(D_{B}-C_{B}\right) / 0.5, A_{A}<C_{A}, B_{A}>D_{A}>A_{A}$.

Let us compare the developing world's mixed strategies of this game for the situation depicted in Figure 3, and compare it to the situation where there is no fairness adjustment at all. Mixed strategies are relevant when there are uncertainties regarding the participation of other countries and decision-makers thus estimate probabilities concerning the counterparts' behaviour. Country group A estimates the likelihoods of country group B's participation $\left(p_{B}\right)$ and non-participation $\left(1-p_{B}\right)$ - and conversely country group A estimates respective likelihoods for country group B $\left(p_{A}\right.$ and 1- $\left.p_{A}\right)$. In order to determine the developing world's mixed strategies in the game depicted by Figure 3, we have to calculate the likelihood $p_{A}{ }^{* H F A}$ ( $p_{A}{ }^{*}$ when no fairness adjustment is made) of participation by country group A, which makes the decision-maker in B indifferent between playing “participation” and "no participation”.

No fairness adjustment:

$$
p_{A}^{*}=\left(1+\frac{C_{B}-D_{B}}{B_{B}-A_{B}}\right)^{-1}
$$

Historical fairness adjustment:

$$
p_{A}^{* H F A}=\left(1+\frac{C_{B}-D_{B}+0.5 \alpha^{H}}{B_{B}-A_{B}-0.75 \alpha^{H}}\right)^{-1}<p_{A}^{*}
$$

Hence, ceteris paribus, the historical adjustment will reduce the likelihood that the developing world will participate in international mitigation efforts in our stylized example depicted in Figure 3 (keep in mind that the lower the $p_{A}^{* H F A}$ threshold, the more likely is a no-participation strategy of the developing world).

Integration of both intention and consequence driven fairness aspects as described in Figures 2 and 3 shows that intention driven fairness aspects support "negative reciprocity" based on consequence driven unfairness (since fairness adjustment takes place in both cases with negative factors), while they tend to mitigate the perception of unfairness caused by negative 
past experiences (as the adjustment factor associated with intention driven fairness is positive in the case of mutual participation).

\subsection{Correcting for Past Unfairness}

An obvious strategy for industrialized countries to raise fairness as perceived by the developing countries is to help to prevent damage in the developing world caused by past GHG emissions. Although the support of adaptation to climate change in developing countries might be an attractive option for industrialized countries to regain trust in these countries, much depends on the way in which the support is provided. Let us distinguish two different cases:

1) Adaptation support is provided by the industrialized world unconditionally, i.e., regardless of individual developing countries' decisions about participation and non-participation in an international agreement on climate change mitigation. Therefore, adaptation funding can be considered to be provided before the negotiation game is played, since it just adjusts downwards former unfair behaviour (as perceived by developing countries). In this case, it has no effect on the intention driven fairness aspects, since the related (intention driven) fairness perception depends on the agents' activities within the negotiation process. Yet, the consequence driven fairness aspects which are based on past experiences, i.e., before the negotiation game was started, are influenced.

2) Adaptation support is provided conditionally on developing countries' participation in the international agreement. This will influence the developing countries' material payoffs within the game in a similar way as local ancillary benefits of climate policy. Positive effects of ancillary benefits on developing countries' willingness to participate in climate change mitigation have been demonstrated by Pittel and Rübbelke (2008). However, despite such a bribe's (via adaptation funds) potential positive influence on developing countries' material payoffs and their participation in international mitigation efforts, the influence of such policies - which are subject to conditions - on developing countries' trust and on intention driven fairness aspects is unlikely to be very positive. As Paavola and Adger (2005: 360) point out: "When agents have plural motivations - of which self-centred welfare maximisation is but one example - and their ability to detect the motivations of other agents is limited, then the act of signalling intentions becomes a means to elicit reciprocal behaviour"; conditionality of industrialized countries' help for developing countries in adapting to climate change might be an inadequate signal from a fairness perspective.

Let us focus on the first case, where adaptation funding influences the developing countries' behaviour mainly via fairness aspects (and not through the provision of ancillary adaptation 
benefits to the developing world). In the case only including consequence driven fairness aspects, as discussed in Subsection 4.2, the influence of a rise in the perceived 'historical' fairness on the likelihood of developing countries participating in international mitigation efforts is positive. If the adaptation support reduces the measure for perceived historical unfairness $\alpha^{H}$, we obtain:

$$
-\frac{d p_{A}^{* H F A}}{d \alpha^{H}}=-\frac{0.5\left(A_{B}-B_{B}\right)+0.75\left(D_{B}-C_{B}\right)}{\left(B_{B}-A_{B}-D_{B}+C_{B}-0.25 \alpha^{H}\right)^{2}}>0 .
$$

Consequently, the likelihood of developing countries' participation will be augmented by a reduction in $\alpha^{H}$ (keep in mind that the higher the $p_{A}^{* H F A}$ threshold, the more likely is a participation strategy of the developing world).

If consequence driven (historical) fairness and intention driven fairness aspects (as depicted in Figures 2 and 3) are both jointly implicated in an additive way, the respective fairness aspects may however run counter. A rise in perceived historical fairness reflected by a decline in $\alpha^{H}$ would mitigate the all-over "negative reciprocity" in a situation where the negotiating parties face unilateral efforts by the developing countries. In this situation, over-all fairness adjustment takes place via the developing countries' adjustment term $\left(F^{H}=-0.75 \alpha^{H}\right)$ associated with consequence driven fairness and the term $\left(F_{B}=-0.5 \alpha_{B}^{I}\right)$ associated with intention driven fairness. Hence, because of the decline in $\alpha^{H}$ over-all unfairness perceived in this situation declines. At the same time "positive reciprocity" in the situation where both agents participate in the international environmental agreement is reinforced, since perceived unfairness declines (or fairness rises) due to the mitigation in the perception of historical unfairness (the developing countries' adjustment term $F^{H}=-0.5 \alpha^{H}$ associated with consequence driven fairness is negative, while the term $F_{B}=+0.75 \alpha_{B}^{I}$ associated with intention driven fairness is positive in the case of mutual participation).

In the case where consequence and intention driven fairness adjustments (as depicted in Figures 2 and 3) are taken into account in an additive way we get:

$$
p_{A}^{* F A}=\left(1+\frac{C_{B}-D_{B}+0.5 \alpha^{H}-0.75 \alpha_{B}^{I}}{B_{B}-A_{B}-0.75 \alpha^{H}-0.5 \alpha_{B}^{I}}\right)^{-1}
$$

Consequently, we obtain

$$
-\frac{d p_{A}^{* F A}}{d \alpha^{H}}=-\frac{0.5\left(A_{B}-B_{B}\right)+0.75\left(D_{B}-C_{B}\right)+0.8125 \alpha_{B}^{I}}{\left(B_{B}-A_{B}-D_{B}+C_{B}-0.25 \alpha^{H}-1.25 \alpha_{B}^{I}\right)^{2}},
$$

which is positive as long as $\alpha_{B}^{I}$ is not too large, i.e., for our parameterization of the model as long as $\alpha_{B}^{I}<\left[0.5\left(B_{B}-A_{B}\right)+0.75\left(C_{B}-D_{B}\right)\right] \frac{1}{0.8125}$. Consequently, both kinds of fairness 
have to be taken into account in the international climate policy arena and it might be beneficial to play fair throughout. A sufficient condition for $-\frac{d p_{A}^{* F A}}{d \alpha^{H}}>0$ is that the game setting including intention driven fairness aspects is of the chicken-type (and hence, it would hold that $\alpha_{B}^{I}<\frac{B_{B}-A_{B}}{0.5}$ and $\alpha_{B}^{I}<\frac{C_{B}-D_{B}}{0.75}$ ).

Yet, as long as the adaptation support is based on global benefit orientation - like in the case of GEF funding via the Strategic Priority "Piloting an Operational Approach to Adaptation” (SPA) as a part of the GEF Trust Fund -, developing countries may not consider this support as fairness-enhancing since industrialized countries benefit from such global benefits in the same way as developing countries. Consequently, especially the support of adaptation projects in the developing world which exert mainly local/regional benefits tends to best serve a mitigation of the historically perceived unfairness. An additional positive effect on fairnessperception could be generated by organizing the international adaptation support in a way that provides strong participation of developing countries in the support mechanisms, ${ }^{25}$ like in the case of the Adaptation Fund where developing countries hold the overall majority of seats in the AF Board. ${ }^{26}$ In contrast, the GEF-lead management of adaptation funds (as in the case of LDCF and SCCF) is considered with scepticism in many developing countries, because the GEF's governance and agenda is regarded as dominated by the industrialized world (see, e.g., Najam, Huq and Sokona 2003: 225).

\section{Concluding Remarks}

International transfers supporting adaptation and mitigation projects in developing countries are an intensely disputed topic, not only in the ongoing international negotiations on climate change, but also in the scientific arena. Adaptation funding is a comparatively new field and many questions concerning its justification, effects, and the best strategies to transfer these funds still remain unanswered. That is why our discussion centred largely on adaptation support. In our analysis we addressed the questions 1) what reasons might drive the industrialized countries' support of climate policy in developing countries and 2) whether current support schemes are appropriate to serve these reasons.

Since climate protection is a global public good, climate protection benefits from projects in the developing world can be enjoyed by industrialized countries in the same way as respective

\footnotetext{
${ }^{25}$ The Copenhagen Accord also announces more equitable structures for governing international adaptation funds: "[n]ew multilateral funding for adaptation will be delivered through effective and efficient fund arrangements, with a governance structure providing for equal representation of developed and developing countries".

${ }^{26}$ For an application of different fairness and equity criteria to evaluate the Adaptation Fund, see Grasso (2010).
} 
benefits of domestic protection activities. Yet, the mitigation activities tend to be less expensive in the developing than in the industrialized world. The GEF mechanism offers a way to exploit such low-cost GHG abatement options in the developing world. The pursuit of more cost-effective abatement internationally as well as the price-influencing effect of the conditional transfers tend to bring about a Pareto-improved global climate change mitigation.

In contrast, adaptation projects mainly produce local or regional benefits, so that the reasons for international transfers supporting adaptation are more ambiguous although - as we discussed - indirect global benefits of adaptation may arise. In general, with respect to these reasons, reference is made to the UNFCCC - which assigns duties for assisting developing countries to the industrialized world - and to the moral obligation for the rich countries which were the main GHG emitters in the past - to help the poor countries to cope with the consequences of climate change. Yet, as we argue, the support of adaptation in developing countries can also be regarded as a kind of confidence-building activity which might help to attain a Pareto-improved global mitigation regime. Positive effects of such confidence building on the prospects of success of international negotiations have been illustrated in normal-form game settings. However, as we demonstrated, the level of confidence building or fairness perceived strongly depends on the way in which transfers are granted. Furthermore, it should be taken into account that different fairness aspects might even run counter.

We argued that adaptation support with global benefit orientation (as has been conducted via the SPA) is less attractive for raising fairness-perceptions in the developing world, while the concepts pursued by LDCF, SCCF and especially by the AF tend to be more appropriate. Transfers raising global benefits are to the advantage of both developed and developing world, while historical fairness enhancement is more targeted on correcting for disadvantages suffered by developing countries. Industrialized countries can mitigate these disadvantages first and foremost by funding adaptation which only (or at least mainly) benefits the developing world. Put it differently, trust of developing countries in industrialized countries may be especially augmented when the developed countries are willing to give up some of their own wealth in order to rectify basic conditions for developing countries.

The AF, in turn, tends to be more attractive for raising the developing world's trust and fairness-perception than the LDCF and the SCCF, because of the stronger involvement of developing countries in its governance structure. Furthermore, many developing countries regard the GEF-managed LDCF and SCCF with scepticism, because they distrust the GEF (owing to the strong influence industrialized countries are imputed to exert on this institution). 
The global-benefit orientation of GEF's financing concepts under the SPA is not only disadvantageous from a confidence-building perspective, but it is obviously also an inappropriate approach for supporting adaptation projects per se. Adaptation projects yield mainly local benefits and if adaptation funding would be aligned with the global-benefit criterion, then - depending on the funding rule (e.g., net incremental cost rule) - insufficient funding might be provided in most cases, because adaptation cost minus domestic benefits in the host region of adaptation might yield negative numbers.

On the grounds of these and related difficulties, the Facility launched funds (LDCF and SCCF) which are not subject to the global-benefit criterion. Here, problems arise from the criterion of additionality of adaptation funding, i.e., adaptation support of industrialized countries should be additional to traditional ODA. The applied proxy (sliding scale) is inappropriate for ascertaining additional cost, but given the complexity and uncertainties involved in assessing additional cost, this proxy might be the better option available.

Finally, it has to be taken into account that the GEF is an evolving organization whose evolution is determined by the expansion of environmental threats and whose changes of objectives are dictated by international environmental policy; the Facility itself has to adapt permanently to new challenges. The global benefit orientation was appropriate in the infant times of the Facility, when international policy largely focused on climate change mitigation activities. Meanwhile international policy also assigned the role of an adaptation-funding entity to the GEF. Climate policies in the shape of adaptation, however, exhibit mainly local benefits and this poses a challenge to the financing framework. The GEF initially responded to this challenge by partly remaining with old strategies (SPA) and partly switching to new instruments (LDCF and SCCF). Meanwhile the GEF has further modified its financing structure and, for the GEF-5 replenishment (2010-2014), all adaptation-related work of the GEF will be financed through the LDCF and SCCF. The fragmentation of adaptation support continues to prevail since additional new funding schemes, e.g., the Adaptation Fund, occurred. Whether the fragmentation and the establishment of new funding entities will help to pursue an efficient international adaptation support remains questionable and as Persson et al. (2009: 71) point out, “As for the Adaptation Fund, it remains to be seen whether delivery of resources will be more effective and efficient than under the GEF-managed adaptation funds.” 


\section{References}

Aakre, S. and Rübbelke, D.T.G. (2010a), "Adaptation to Climate Change in the European Union: Efficiency vs. Equity Considerations," Environmental Policy and Governance, 20, 159-179.

Aakre, S. and Rübbelke, D.T.G. (2010b), “Objectives of Public Economic Policy and the Adaptation to Climate Change," Journal of Environmental Planning and Management, 53, 767-791.

Adger, W.N. (2001), "Scales of Governance and Environmental Justice for Adaptation and Mitigation of Climate Change,” Journal of International Development, 13, 921-931.

Adger, W.N.; Benjaminsen, T.A.; Brown, K. and Svarstad, H. (2001), "Advancing a Political Ecology of Global Environmental Discourses,” Development and Change, 32: 681-715.

Althammer, W. and Buchholz, W. (1993), "Lindahl-equilibria as the Outcome of a Noncooperative Game,” European Journal of Political Economy, 9, 399-405.

Anantram, K. and Noronha, L. (2005), Financing Adaptation, Discussion Paper, The Energy and Resource Institute, New Delhi.

Arrow, K.J. (2007), “Global Climate Change: A Challenge to Policy,” Economists' Voice, June.

Barrett, S. (2007a), Equity, the Stern Review and What Should We Do About Climate Change, Contribution to the blog ClimatePolicy.org - An American Meteorological Society Project. Available online at: http://www.climatepolicy.org/?p=13

Barrett, S. (2007b), “Proposal for a New Climate Change Treaty System,” Economists' Voice, October.

Barrett, S. (2008a), "Climate Treaties and the Imperative of Enforcement," Oxford Review of Economic Policy, 24, 239-258.

Barrett, S. (2008b), Dikes v. Windmills: Climate Treaties and Adaptation, paper presented at the workshop 'The Environment, Technology and Uncertainty' of the Ragnar Frisch Centre for Economic Research, Oslo.

Bastianoni, S.; Pulselli, F.M. and Tiezzi, E. (2004), “The Problem of Assigning Responsibility for Greenhouse Gas Emissions,” Ecological Economics, 49, 253-257.

Bergstrom, T.C.; Blume, L. and Varian, H. (1986), “On the Private Provision of Public Goods,” Journal of Public Economics, 29, 25-49.

Boadway, R. (1997), "Public Economics and the Theory of Public Policy,” Canadian Journal of Economics, 30, 753-772.

Boadway, R.; Song, Z. and Tremblay, J.-F. (2007), "Commitment and Matching Contributions to Public Goods,” Journal of Public Economics, 91, 1664-1683.

Bolton, G.E. and Ockenfels, A. (2005), “A Stress Test of Fairness Measures in Models of Social Utility,” Economic Theory, 25, 957-982.

Buchholz, W. and Konrad, K.A. (1995), "Strategic Transfers and Private Provision of Public Goods,” Journal of Public Economics, 57, 489-505.

Buchholz, W.; Cornes, R.C. and Rübbelke, D.T.G. (2011), "Interior Matching Equilibria in a Public Good Economy: An Aggregative Game Approach,” Journal of Public Economics, forthcoming.

Burton, I.; Diringer, E. and Smith, J. (2006), Adaptation to Climate Change: International Policy Options, PEW Center on Global Climate Change, Arlington. 
Camerer, C.F. (1997), "Progress in Behavioral Game Theory," Journal of Economic Perspectives, 11, 167-188.

Camerer, C.F. and Thaler, R.H. (2003), "In Honor of Matthew Rabin: Winner of the John Bates Clark Medal, Journal of Economic Perspectives, 17, 159-176.

Campbell-Lendrum, D. and Woodruff, R. (2007), Climate Change: Quantifying the Health Impact at National and Local Levels, WHO Environmental Burden of Disease Series No. 14, A. Prüss-Üstün and C. Corvalán (eds.), World Health Organization, Geneva.

Cornes, R.C. and Sandler, T. (1996), The Theory of Externalities, Public Goods and Club Goods, Cambridge University Press, Cambridge.

COWI and IIED (2009), Operation of the Least Developed Countries Fund For Adaptation to Climate Change, Joint External Evaluation, Ministry of Foreign Affairs of Denmark.

Edenhofer, O.; Knopf, B.; Luderer, G.; Steckel, J. and Bruckner, T. (2011), "More Heat Than Light? On the Economics of Decarbonisation,” in: K.D. John and D.T.G. Rübbelke (eds.), Sustainable Energy, Routledge, Abingdon, New York, 70-108.

Ekins, P. (1996), "The Secondary Benefits of $\mathrm{CO}_{2}$ Abatement: How Much Emission Reduction Do They Justify?,” Ecological Economics, 16, 13-24.

Falk, A. and Fischbacher, U. (2006), “A Theory of Reciprocity,” Games and Economic Behavior, 54, 293-315.

Falkinger, J. (1996), "Efficient Private Provision of Public Goods by Rewarding Deviations from Average,” Journal of Public Economics, 62, 413-422.

Fehr, E. and Gächter, S. (2000), "Fairness and Retaliation: The Economics of Reciprocity,” Journal of Economic Perspectives, 14, 159-181.

Geanakoplos, J.; Pearce, D. and Stacchetti, E. (1989), "Psychological Games and Sequential Rationality," Games and Economic Behavior, 1, 60-79.

GEF (2006), Programming Paper for Funding the Implementation of NAPAs under the LDC Trust Fund, GEF/C.28/18, GEF Council Meeting, June 6-9, 2006.

GEF (2010a), Final GEF-5 Programming Document, GEF/R.5/25/CRP.1, Fifth Meeting for the Fifth Replenishment of the GEF Trust Fund, March 9-10, 2010, Rome.

GEF (2010b), Status Report on the Least Developed Countries Fund and the Special Climate Change Fund, GEF/LDCF.SCCF.8/Inf.2/Rev.1, May 31, 2010.

Gielen, D. and Chen, C. (2001), "The $\mathrm{CO}_{2}$ Emission Reduction Benefits of Chinese Energy Policies and Environmental Policies: A Case Study for Shanghai, Period 1995-2020,” Ecological Economics, 39, 257-270.

Grasso, M. (2007), “A Normative Ethical Framework in Climate Change,” Climatic Change, 81, 223-246.

Grasso, M. (2010), “An Ethical Approach to Climate Adaptation Finance,” Global Environmental Change, 20, 74-81.

Guttman, J. (1978), “Understanding Collective Action: Matching Behavior,” American Economic Review, 68, 251-255.

Heintz, R.J. and Tol, R.S.J. (1996), Secondary Benefits of Climate Control Policies: Implications for the Global Environment Facility, CSERGE Working Paper GEC 96-17, London.

Ikeme, J. (2003), "Equity, Environmental Justice and Sustainability: Incomplete Approaches in Climate Change Politics,” Global Environmental Change, 13, 195-206. 
IPCC (2001a), Climate Change 2001 - Impacts, Adaptation, and Vulnerability, Cambridge University Press, Cambridge.

IPCC (2001b), Climate Change 2001 - Mitigation, Cambridge University Press, Cambridge.

IPCC (2007a), Climate Change 2007 - Impacts, Adaptation, and Vulnerability, Cambridge University Press, Cambridge.

IPCC (2007b), Climate Change 2007 - Synthesis Report. IPCC, Geneva.

Jayaraman, R. and Kanbur, R. (1999), "International Public Goods and the Case for Foreign Aid,” in: I. Kaul; I. Grunberg and M.A. Stern (eds.), Global Public Goods, Oxford University Press, New York, 418-435.

Kahneman, D.; Knetsch, J.L. and Thaler, R.H. (1986a), "Fairness and the Assumptions of Economics,” Journal of Business, 59, S285-S300.

Kahneman, D.; Knetsch, J.L. and Thaler, R.H. (1986b), "Fairness as a Constraint on Profit Seeking: Entitlements in the Market," American Economic Review, 76, 728-741.

Klein, R.J.T.; Schipper, E.L.F. and Dessai, S. (2005), "Integrating Mitigation and Adaptation into Climate and Development Policy: Three Research Questions," Environmental Science \& Policy, 8, 579-588.

Klein, R.J.T.; Eriksen, S.E.H.; Næss, L.O.; Hammill, A.; Tanner, Th.M.; Robledo, C. and O’Brien, K.L. (2007), "Portfolio Screening to Support the Mainstreaming of Adaptation to Climate Change into Development Assistance,” Climatic Change, 84, 23-44.

Lange, A.; Vogt, C. and Ziegler, A. (2007), “On the Importance of Equity in International Climate Policy: An Empirical Analysis,” Energy Economics, 29, 545-562.

Le Goulven, K. (2008), Financing Mechanisms for Adaption, Secretariat to the Commission on Climate Change and Development, Stockholm.

Madani, K. (2009), “Game Theory and Water Resources,” Journal of Hydrology, 381, 225238.

Markandya, A. and Chiabai, A. (2009), "Valuing Climate Change Impacts on Human Health: Empirical Evidence from the Literature," International Journal of Environmental Research and Public Health, 6, 759-786.

Möhner, A. and Klein, R.J.T. (2007), The Global Environmental Facility: Funding for Adaptation or Adapting to Funds?, Working Paper, Stockholm Environment Institute, Stockholm.

Musgrave, P.B. (2008), “Comments on Two Musgravian Concepts,” Journal of Economics and Finance, 32, 340-347.

Musgrave, R.A. (1959), The Theory of Public Finance, McGraw Hill, New York.

Musgrave, R.A. (2008), "Public Finance and the Three Branch Model,” Journal of Economics and Finance, 32, 334-339.

Müller, B. (2008), International Adaptation Finance: The Need for an Innovative and Strategic Approach, Working Paper, EV 42, Oxford Institute for Energy Studies.

Najam, A.; Huq, S. and Sokona, Y. (2003), “Climate Negotiations Beyond Kyoto: Developing Countries Concerns and Interests,” Climate Policy, 3, 221-231.

Neumayer, E. (2000), "In Defence of Historical Accountability for Greenhouse Gas Emissions,” Ecological Economics, 33, 185-192.

Paavola, J. and Adger, W.N. (2005), “Institutional Ecological Economics,” Ecological Economics, 53, 353-368. 
Paavola, J. and Adger, W.N. (2006), “Fair Adaptation to Climate Change,” Ecological Economics, 56, 594-609.

Pearce, D. (1995), Blueprint 4 - Capturing Global Environmental Value, Earthscan Publications Limited, London.

Persson, Å.; Klein, R.J.T.; Kehler Siebert, C.; Atteridge, A.; Müller, B.; Hoffmaister, J.; Lazarus, M. and Takama, T. (2009), Adaptation Finance under a Copenhagen Agreed Outcome, Research Report, Stockholm Environment Institute.

Pittel, K. and Rübbelke, D.T.G. (2008), "Climate Policy and Ancillary Benefits - A Survey and Integration into the Modelling of International Negotiations on Climate Change," Ecological Economics, 68, 210-220.

Pittel, K. and Rübbelke, D.T.G. (2010), "Transitions in the Negotiations on Climate Change: From Prisoner's Dilemma to Chicken and Beyond,” International Environmental Agreements: Politics, Law and Economics, Online First.

Rabin, M. (1993), "Incorporating Fairness into Game Theory and Economics,” American Economic Review, 83, 1281-1302.

Rabin, M. (1997), Fairness in Repeated Games, Working Paper No. 97-252, Department of Economics, University of California at Berkley.

Ringius, L.; Torvanger, A. and Underdal, A. (2002), "Burden Sharing and Fairness Principles in International Climate Policy," International Environmental Agreements: Politics, Law and Economics, 2, 1-22.

Schelling, T.C. (1992), “Some Economics of Global Warming,” American Economic Review, 82, 1-14.

Schelling, T.C. (1997), “The Cost of Combating Global Warming,” Foreign Affairs, 76, 8-14.

Shue, H. (1999), “Global Environment and International Inequality,” International Affairs, 75, 531-545.

Smit, B.; Burton, I.; Klein, R.J.T. and Street, R. (1999), "The Science of Adaptation: A Framework for Assessment," Mitigation and Adaptation Strategies for Global Change, 4, 1999-213.

Smith, V.L. (2003), "Constructivist and Ecological Rationality in Economics," American Economic Review, 93, 465-508.

Stern, N. (2007), The Economics of Climate Change - the Stern Review, Cambridge University Press, Cambridge.

UNDP (2009), Evaluation of UNDP Work with Least Developed Countries Fund and Special Climate Change Fund Resources, Evaluation Office, July 2009.

Van Drunen, M.; Bouwer, L; Dellink, R.; Gupta, J.; Massey, E. and Pauw, P. (2009), Financing Adaptation in Developing Countries - Assessing New Mechanisms, IVM-report W09/02, University Amsterdam.

World Bank (2006), Clean Energy and Development: Towards an Investment Framework, World Bank, Washington. 


\section{Appendix}

\section{Categorization of Effects of Adaptation and Mitigation Policy}

The categorization in Table A.1 of effects of adaptation and mitigation policies is stylized, and there may be cases which do not fit exactly in one category, i.e., they are intermediate cases.

\begin{tabular}{|c|c|c|c|c|}
\hline & \multicolumn{2}{|c|}{ Direct Benefits } & \multicolumn{2}{|c|}{ Indirect Benefits } \\
\hline & $\begin{array}{c}\text { Immediate } \\
\text { Benefits }\end{array}$ & $\begin{array}{l}\text { Delayed } \\
\text { Benefits }\end{array}$ & $\begin{array}{c}\text { Immediate } \\
\text { Benefits }\end{array}$ & $\begin{array}{l}\text { Delayed } \\
\text { Benefits }\end{array}$ \\
\hline $\begin{array}{c}\text { Mitigation } \\
\text { Policy }\end{array}$ & $\begin{array}{l}\text { - local/regional } \\
\text { ancillary effects }\end{array}$ & $\begin{array}{l}\bullet \text { prevention of } \\
\text { climate change and } \\
\text { associated negative } \\
\text { global impacts }\end{array}$ & $\begin{array}{l}\text { - local/regional } \\
\text { follow-up effects }\end{array}$ & $\begin{array}{l}\text { - prevention of } \\
\text { negative global } \\
\text { follow-up effects } \\
\text { (of direct climate } \\
\text { change impacts) } \\
\text { - local/regional } \\
\text { follow-up effects }\end{array}$ \\
\hline $\begin{array}{c}\text { Adaptation } \\
\text { Policy }\end{array}$ & $\begin{array}{l}\text { - local/regional } \\
\text { prevention of } \\
\text { climate change } \\
\text { damage } \\
\text { - local/regional } \\
\text { ancillary effects }\end{array}$ & & $\begin{array}{l}\text { - prevention of } \\
\text { negative global } \\
\text { follow-up effects } \\
\text { (of direct climate } \\
\text { change impacts) } \\
\text { - local/regional } \\
\text { follow-up effects }\end{array}$ & \\
\hline
\end{tabular}

Table A.1: Categorization of Adaptation and Mitigation Policy Effects.

\section{Direct Effects}

There is a delay in the reaction of the climatic system to GHG emission changes, such that the positive effects of today's activities to mitigate climate change will be first perceived in about half a century. In contrast the ancillary effects of climate change mitigation, like the reduction in local air pollution, arise almost immediately and provide so-called ancillary benefits nearly without delay. ${ }^{27}$ In contrast, adaptation has in general only local/regional direct impacts, which are not delayed. A dike immediately protects a region after its construction is completed. Furthermore, the dike protects this region also against such flooding that would as well have

\footnotetext{
${ }^{27}$ As Ekins (1996: 21) stresses: “Aggressive $\mathrm{CO}_{2}$ abatement would not only avoid these serious risks for the future; it is also clear that it would yield substantial benefits through the reduction of other pollution damages here and now."
} 
occurred without climate change and this protection can be regarded as ancillary effects of the adaptation measure in the shape of dike construction.

\section{Indirect Effects}

Adaptation in the shape of the establishment of a transboundary information dissemination system on the occurrence of extreme events could help to prevent major damage to people and the uncontrolled migration of people fleeing the affected regions. The positive effects of this system are attainable immediately after its build-up. The effects of this system are partly indirect, and partly direct. On the one hand, the system prevents some of the direct damage caused by global warming, e.g., the death of people in the course of an extreme weather event, ${ }^{28}$ by warning the people and hence allowing them to be better prepared. On the other hand, because the early warning allows people to organize shelters in advance of the incidence, conflicts and unrest - which are more indirect effects of climate change (follow-up effects) - can be prevented which would otherwise be caused by crowds of people fleeing to other regions in an uncoordinated way. In the regions where the refugees arrive, conflicts may arise, e.g., because of a shortage of water and food. Such conflicts can either be restricted to a regional scale, but they may also spread internationally. A similar argumentation applies to climate change mitigation activities, since in these cases the occurrence of damages can be more basically prevented, and consequently the positive indirect impacts observable in the adaptation policy case also arise in the mitigation policy case. Yet, the indirect mitigationrelated impacts are occurring with a delay, like the direct global effects of climate policy do. In contrast, the follow-up effects of the direct ancillary effects of mitigation policy exhibit almost no delay. Reforestation, for example, does not only sequester carbon and consequently mitigate climate change: it can also preserve regional water availability (which is an ancillary effect of the mitigation policy). The prevention of water scarcity may in turn prevent people from fleeing to other regions and from potentially causing unrest there.

\footnotetext{
${ }^{28}$ For a classification of direct and indirect health impacts of extreme weather events caused by climate change, see Markandya and Chiabai (2009: 762). As Campbell-Lendrum and Woodruff (2007: 18) stress: "Ideally, all health outcomes which are directly or indirectly linked to climate variability and climate change should be considered.”
} 


\title{
BC3 WORKING PAPER SERIES
}

\author{
Basque Centre for Climate Change (BC3), Bilbao, Spain
}

The BC3 Working Paper Series is available on the internet at the following addresses:

http://www.bc3research.org/lits_publications.html

$\underline{\text { http://ideas.repec.org/s/bcc/wpaper.html }}$

BC3 Working Papers available (see website for full list):

2010-06

Ibon Galarraga, Mikel González-Eguino and Anil Markandya: Evaluating the Role of Energy Efficiency Labels: the Case of Dish Washers

2010-07

Luis M. Abadie, Mikel González-Eguino and José M. Chamorro: Optimal Abandonment of Coal-Fired Stations in the EU

2010-08

Dirk Rübbelke and Stefan Vögele: Impacts of Climate Change on European Critical Infrastructures: The Case of the Power Sector

Roger Fouquet: The Sustainability of 'Sustainable' Energy Use: Historical Evidence on the Relationship between Economic Growth and Renewable Energy

2010-10

Karen Pittel and Dirk Rübbelke: Energy Supply and the Sustainability of Endogenous Growth

2010-11

2010-12

Ramon Arigoni Ortiz, Alexander Golub, Oleg Lugovoy, Anil Markandya and James Wang: The DICER Model: Methodological Issues and Initial Results.

Elena Ojea, Julia Martin-Ortega and Aline Chiabai: Classifying Ecosystem Services for Economic Valuation: the Case of Forest Water Services

2010-13

Aline Chiabai, Chiara Travisi, Anil Markandya, Helen Ding, and Paulo Nunes: Economic Assessment of Forest Ecosystem Services Losses: Cost of Policy Inaction

2010-14

Kaysara Khatun: Competing Ecosystem services: an Assessment of Carbon and Timber in the Tropical Forests of Central America

Karen Pittel and Dirk Rübbelke: Local and Global Externalities, Environmental Policies and Growth

2010-16

2010-17

Margherita Grasso, Matteo Manera, Aline Chiabai, and Anil Markandya: The Health Effects of Climate Change: A Survey of Recent Quantitative Research

Luis Mari Abadie, Ramon Arigoni Ortiz and Ibon Galarraga: The Determinants of Energy Efficiency Investments in the U.S.

2010-18

2011-01

Aline Chiabai, Dirk Rübbelke and Lisa Maurer: ICT Application in the Research for Environmental Sustainability

2011-02

Roger Fouquet: Long Run Dynamics of Energy-Related External Costs

Dirk Rübbelke: International Support of Climate Change Policies in Developing Countries: Strategic, Moral and Fairness Aspects 